\title{
The Impact of the Perceived Service Quality on Revisit Intention in the Tourism Industry: A Conceptual Framework of Strategic Approach and Analysis
}

\author{
Lola Kleisari
}

Evangelia N. Markaki

\section{Abstract}

Service quality (SQ) is of strategic importance in the hospitality sector from both company's and customers' viewpoint. Hence, it is crucial for every organization's function and survival in such a competitive era. As proven in the literature, competitive advantage apart of being an indicator of a firm's successful performance, it is an indicator of a firm's profitability. Through a review in literature there are five hypotheses formed accordingly to the five dimensions of service quality that affect guest retention. The study's objectives are 1) to identify the dominant guest-defined characteristic of service quality 2) to examine its strategic impact on revisit intention and 3) to identify whether any differences occur between Greek and European guests in the way they perceive service quality. The aim is to provide strategic insights regarding the perceptions of service quality among Greek and European guests, as well as to clarify if there are any differences in the way their perceptions are formed in order to contribute to the literature with regard to the Greek hospitality sector. Questionnaires, based on the SERVQUAL model will be used, in order to collect data from guests that have previously visited a 4 or 5 star hotel. Upon collection, the data will be analyzed with the use of the SPSS program. This paper follows the standards of similar surveys in the industry focused on the measurement of Service Quality. Though, little attempt can be spotted in regards to service quality in 4 and 5 star hotel sector in Greece and give practical directions for strategic design and implementation of services.

Keywords: customer satisfaction, service quality, SERVQUAL, guest culture, customer retention, strategic design, statistics

\section{Introduction}

Service quality (SQ) is of great importance in the hospitality sector from both managers' and customers' viewpoint. Hence, it is crucial for every organization's function and survival in such a competitive era(Al-Ababneh, 2016).As proven in the 
literature, competitive advantage apart of being an indicator of a firm's successful performance, it is an indicator of a firm's profitability (Kim and Oh, 2004).Due to the perishability and the nature of the services, those functions are different in manufacturing and service industry, whereas, in the latter, the relationship of the product and the guest (consumer) is formed at the same time of the consumption (e.g. direct contact of the front office agent and the guest) (Kandampully, 2006). The intangibility of the services sector can rend the measurement of objectively noncountable elements, such as quality, a complex task. The hospitality literature is full of practices that affect guest retention and concludes that it is a process that starts from "within" the organization. For example, internal communication and employee retention can be a factor that affects guest retention(Buhalis, 2001; Kim, Knutson and Han, 2015) In addition, Jung and Woon, (2013) suggest that it has a positive echo on customer satisfaction and loyalty and is related to the firm's performance and image. (Chi and Gursoy, 2009; Jung and Woon, 2013).

To begin with, a brief historical review with regard to the international tourism development, shows that nevertheless historical and political situations such as the world fuel crisis on the late 70s and the Gulf War at the late 80s, worldwide tourism kept rising, particularly in Europe, which remained the main touristic destination, regardless the fact that the less developed regions of the world faced a decline. Overall, it has been proved that the effect on tourism was for a short period of time and moreover, the tourist product is considered as a key source for investment for both the consumer and the government (Witt and Moutinho, 1995).

'Sea and Sun' concept has been marking the Greek hospitality sector since 1960. However, little effort has been made to take advantage of this concept through a structured business scheme in order to diversify the Greek tourism product with the intention to expand it in all its other forms (Papadimitriou, Boussia and Trakas, 2016). By exploring the keywords: 'service quality' a handful of studies have been found regarding leisure and recreation tourism and more specifically sports and festivals (Barlas, Mantis and Koustelios, 2010; Costa and Glinia, 2004; Papadimitriou, 2013; Theodorakis, Goulimaris and Gargalianos, 2003). However, little emphasis has been given on how customers perceive service quality in the Greek hotel sector, which was the stepping stone for the study's conceptualization. A SWOT Analysis performed by Buhalis (2001), demonstrates that despite the numerous strengths of Greek tourism, e.g. cultural heritage, family orientation, natural surroundings, local products, the weaknesses underlined need further attention in terms of operations like marketing and management in the industry. Given the above, this paper will focus on the marketing operations in the hotel industry, searching from the customer's viewpoint about service expectations in a continental framework (Buhalis, 2001).

A handful of studies have enriched the literature regarding guest satisfaction and quality of the services provided in the hotel industry. However, it remains an infinite debate which are the key attributes that drive the guests to return in hotels. Initially, 
this paper aims to identify how Greeks and other European tourists perceive service quality in the hospitality industry and then how it affects both Greek and other European guests regarding the intention to revisit. Moreover, a stimulated study by Luo and Qu (2016), found out that Western culture differs from the Eastern one in the way they perceive service quality in the hotel industry, with the first to be more likely to generate positive feedback. The current study seeks to investigate whether this phenomenon applies to guests from Greece and other European countries, towards the Greek hotel sector. This is stressed due to the fact that even within the Western culture with diverse components, differences can be found.

Therefore, the research questions of the study are the following:

Which are the key elements of service quality that define guest satisfaction and revisit intention?

Is thenatives' perception of the Greek hotel industry anydifferent compared to the Europeans' one?

A review in literature regarding world perceptions of service quality will be illustrated including studies from all over the world.Secondary research on the perceptions of service quality is gathered to demonstrate findings from the 5 continents. At a next stage, a reference is made upon service quality measurement tools, with emphasis on the one that the author will be using in this paper. Furthermore, the study's conceptual framework will be formed followed by a presentation of the research methodology that will be applied in this paper,in order to conclude in the findings.

\section{Services marketing}

Hospitality industry is of great importance in terms of income generation and employment, however, little emphasis has been given in the relation between hospitality and services marketing, a field that lacks two-way communication as far as it concerns the literature. Hospitality is characterized by the strong human element, thus this sector should be covered more thoroughly by reviewing the constituency model that incorporates its internal and interactive marketing activities (Baker and Magnini, 2016). In the hospitality industry, "marketing is a term often used when referring to selling and advertising" (Weane and Morrison, 2013, pp.18). However, this definition does not indicate all the marketing process, instead, it refers to just two major aspects of it. The origin of the definition of the term 'Marketing' derives from American Marketing Association which states that:"Marketing is the activity, set of institutions, and processes for creating, communicating, delivering, and exchanging offerings that have value for customers, clients, partners, and society at large" (AMA, 2008). 


\section{Exploring the variable of Guest's Culture}

Culture is one's belonging and heritage and it affects the way he/she perceives and experiences the world. Apart from perceptions and experiences, it affects decisions and behaviours. Thus, there is a systematic relationship between culture and the service provider. More specifically, Weiermair, 2000, explored the impact of culture in customers (tourists) perceptions of service quality and in the marketing of tourism services, concluding that an international approach should be integrated as to enhance competitiveness and to be able to meet different guests' expectations (Weiermair, 2000).

\section{Service quality and world perceptions}

There is not a single definition for the term "quality".Thus, its significance is of great importance in the hospitality industry in terms of the relationship between administration and customers. The understanding of this terminology will provide knowledge to the organization so as to improve its services and consecutively to determine its strategy towards customer satisfaction (Ghobadian, et al. 1994).

Quality, as a concept, it is complex to define. It is a field that aroused gradually and steadily throughout the centuries. In the 18th and 19th century its control processes were executed in a more informal way, until it reached its recent form as "the strategic quality management". (Garvin, 1988) "Quality control evaluates actual quality by comparing performance to quality goals and then acting on the detected differences. Based on the process control system established in the planning phase, quality control is part of the quality management process." (Pizam and Holcomb, 2008, pp. 228)

- Quality can be perceived by a consumer-based prism as well as an expert-based one. The ideal service perceived by the consumer is different from an expert, with the second to put emphasis on the standards from an internal point-of-view. In addition, satisfaction highlights the customer experience and it affects directly the consumer (Torres, 2014).

Literature has shown that both employees and customers benefit from the implementation of the principles of Total Quality Management (Benavides-Velasco, Quintana-Garcia and Marchante-Lara, 2014).Various authors, by measuring hotel service quality in China, Iran and New Zealand, agree that the quality of services positively affects customer loyalty since customer's emotions are highly influenced by the level of experience provided. Plus, positive customer's perceptions towards service experience raise customer satisfaction (Ali, Amin and Cobanoglu, 2016; Hosseini, Zainal and Sumarjan, 2015; Kandampully and Suhartanto, 2013).

Regarding revisit intention, Kandampully and Suhartanto (2013),highlighted that housekeeping satisfaction is determinant to the customer's intention to revisit and recommend.Adding to it, authors studying the hotel sector in the UK note that room cleanliness and appearance is a prerequisite forrevisit intention (Ramanathan and 
Ramanathan, 2011).The above statement is in agreement with Ingram's and Daskalaki's assumption back in 1999, that tangibles (the personnel appearance, room cleanliness, equipment, and facilities provided along with Information Technology (IT) materials) are the ultimate satisfaction characteristic for a guest in the hotel sector in Greece, by reviewing hotels in Crete. In this way, the study's first hypotheses is formed:

H1: Customer retention relies on tangibles.

This hypothesis is however, opposing to Minh, et al. (2015), in terms of the dominant dimension of service quality that positively affects guests. By measuring guest satisfaction in Vietnamese hotel industry, the above authors came to the conclusion that tangibles is the characteristic with the less consequences on guests' satisfaction. In resort and hotel spa sector in China, reliability and responsiveness ranked as the key elements for customer satisfaction towards the service provider, whereas surprisingly, tangibles ranked as the least important factor (Lo, Wu and Tsai 2015).

Furthermore, research, in the restaurant sector, reveals that empathy and reliability are the ultimate dimensions of guests' perceptions and can enhance their satisfaction (Lee and Hing, 2015).In astudy,20 years earlier, Martin,(1995),revealed that reliability was the ultimate dimension from both management and employee viewpoint. This is also confirmed by a survey of Cappadocia's hotel industry, ranks empathy as being in the first place of guest-defined perceptions whilst evaluating service quality (Yilmaz, 2009).

\section{H3: Customer retention relies on Reliability.}

\section{H4: Customer retention relies on Responsiveness}

In a theoretical framework, Pizam, (2015), explored the term "Empathy" and its implication in real-life cases between the service providers and consumers. He examined two sectors: luxury hotels and hospitals. In both sectors he found out that Empathy is not a prerequisite skill in order to deliver high-quality standards in service; thus he stated that the "mystery ingredient" is Culture. In contrast, a recent study, by Christou et al.(2019), explored the relationship between guest and host in terms of empathy and perception of emotions while interacting with the service providers (hosts). The impact on both found to be imperative. Management should protect employee and employee and guest, respectively, must set limits to their transactions (Christou, Avloniti and Farmaki, 2019).

H2: Customer retention relies on Empathy.

Interestingly, research by Worsfold et al. (2016) in a large global hotel chain concludes that providing a hotel with only quality services is not enough to attract and keep the customer. What customers value is not what managers think most of the time (Worsfold et al. 2016). There are more factors that affect service quality, those of service context and time. This is to say that the guests' impressions vary according 
to the time frame and the context of service and should not be crystallized (Strombeck and Shu 2014).

\section{H5: Customer retention relies on Assurance.}

Customer's satisfaction affect more than a part of a company. It is rather difficult to predict whether customer satisfaction derives from the quality provided by an organization, in this case a hotel. In terms of customer satisfaction, Lewis, (1987), came to the conclusion that it does not necessarily mean that a customer can be dissatisfied with the company, but, having a tendency to "succumb" to competition within the industry. Given the above statement, each company should focus on improving its services by meeting and exceeding customers' expectations by focusing on the elements that enhance customer loyalty. Guest-defined perceptions of quality have a positive echo on customers' loyalty with the brand as well as intention to revisit and recommend (Janinskas, et al. 2016). Furthermore, this is in accordance with a study conducted in 2009 by Hu, Kandampully and Juwaheer, regarding the impact of high standards of quality on the perceived value of the firm with the one complementing the other. By increasing the competitiveness, hotels increase the customers' perceived value, satisfaction and retention. Therefore, high standards of quality lead to high perceptions of quality.

\section{Service quality: Measurement Tools}

Service quality as an element of obtaining competitive advantage has been strongly argued in the field of hospitality literature. Previous studies have introduced and tested service quality models, as an effective way of measuring guest satisfaction. Spencer and Crick (2011) suggest that "QFD flowdown process" is the best model for service quality. By monitoring step-by step, both employees and managers activities in the spectrum of the transformation process (input-processes-output), it is a way to ensure the minimum level of guest satisfaction is met (Spencer and Crick, 2011).

Another model, the SERVQUALOYAL, was introduced by Luo, and Qu (2016), in order to specify and categorize the findings in the loyalty frame. The aim is to measure both the expected and the experienced loyalty from the customer's point of view (Janinskas, et al. 2016).

According to Parasuraman, Berry and Zeithaml, (1988), customer perceptions of quality can be assessed by a 22-item instrument (SERVQUAL), a tool that is used in both retail and service industries. The testing of the modified SERVQUAL scale is applied in a number of studies in the $20^{\text {th }}$ and $21^{\text {st }}$ century in the hotel and restaurant industry, providing insights and implications on the hospitality marketing sector (Ekinci,Prokopaki and Cobanoglu, 2003; Minh, et al., 2015; Murphy, et al., 2007; Lee and Hing, 1995).Originally, the SERVQUAL scale, is divided in 10 elements (Tangibles, Reliability, Responsiveness, Competence, Courtesy, Credibility, Security, Access, Communication, and Understanding) which later on formed the term RATER, a 
shorter definition of Reliability, Assurance, Tangibles, Empathy and Responsiveness (Pizam, 2015).

Each of thosedimensions characterizes the quality of a service:

Reliability- the ability to provide what a company has promised.

Assurance- the ability of the company staff to "inspire trust and confidence".

Tangibles- the personnel appearance, equipment, and facilities provided along with Information Technology (IT) materials.

Empathy- emotionalattention and considerations regarding guest's needs.

Responsiveness- the readiness of the staff to facilitate guest's needs with an honest "willingness" to assist them(Eshetie, et al., 2016; Pizam, 2015).

Even though, the SERVQUAL instrument is widely used for assessing the gaps in service quality, many researchers argue to the extent of its validity as a measurement tool. Williams, (1998), states that SERVQUAL should be combined with other tools in order to measure service quality and should not be considered a one-way path. Gronroos, (1984), introduced another model as an attempt to find out what customers perceive as service quality. The dimensions of this model were built upon the following variables:

- The perceived and the expected service.

- The firm's promises and the product performance.

- The "technical quality" and the "functional quality" (Gronroos, 1984, p.39).

- The firm's image, as an important factor in the way customers perceive the organization.

Perceived service quality is greatly based on the "functional quality" which indicates the way a service is delivered to the consumer. It is subjective compared to the "technical quality" which is objective. Furthermore, image is an important dimension of quality that affects the customer's perception as it can serve as an indicator of good or bad service in customer's mind. Satisfied customers are more likely to excuse a bad firm's performance due to their perception of its good image. The opposite though does not apply (Gronroos, 1984).

Modifications and additions have followed the original SERVQUAL instrument. An example is HOLSERV instrument, which is a format that uses the elements of the original SERVQUAL, whilst adding 8 new elements. An Australian hospitality industry study indicates that employees as the human factor, is the strongest indicator of service quality. HOLSERV is recommended for managers (Mai, Dean and White, 1999). Another model is SERVPERF which was employed to measure service quality and guest satisfaction in hotels in Cyprus (Karatepe and Avci, 2002).

\section{The Conceptual Framework}

Through a review in literature there are five hypotheses formed accordingly to the five dimensions of service quality that affect guest retention. As stated in the 
introduction, the study's objectives are 1) to identify the dominant guest-defined characteristic of service quality 2) to examine its impact on revisit intention and 3) to identify whether any differences occur between Greek and European guests in the way they perceive service quality.

Finally, this paper seeks to confirm whether this statement is indicative towards the hotel sector in Greece. For the study's purposes, a moderated mediation model is developed to illustrate the elements that are under investigation and their impact on revisit intention examining both native and other European guests 'perceptions. Two identical models are created, as below:

\section{Figure 1: Guests: the conceptual framework}

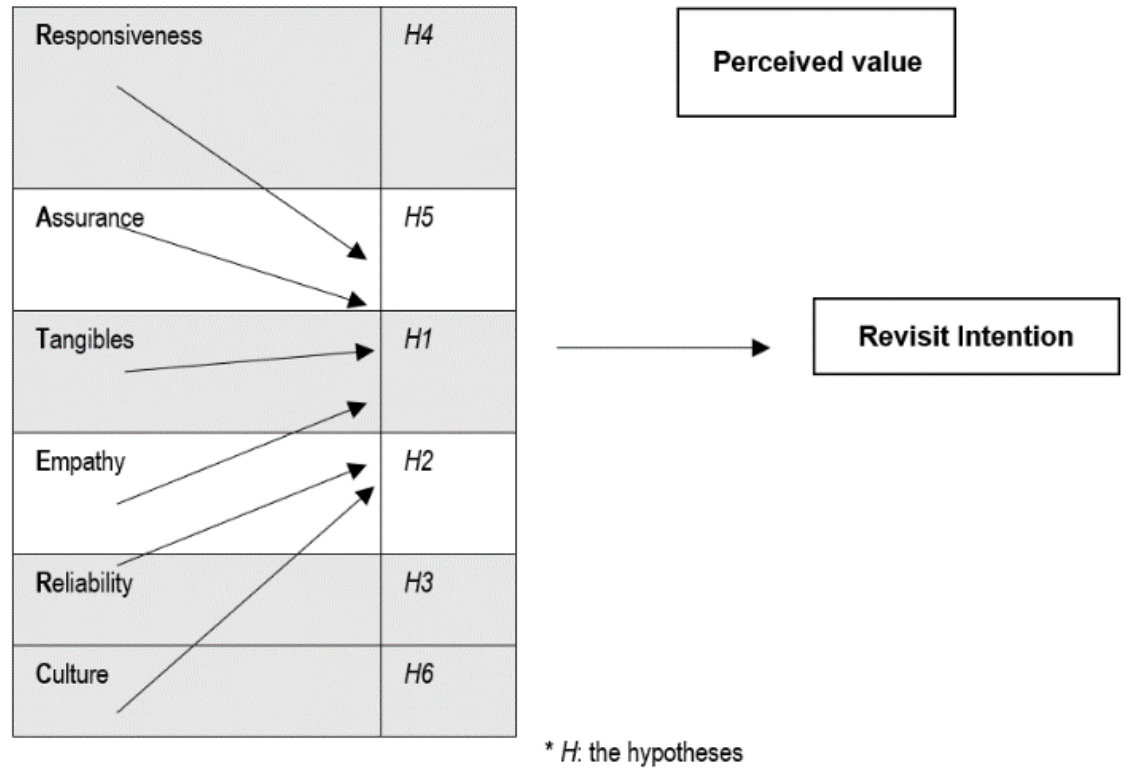

\section{Methodology}

\section{Research Philosophy}

In research, methodology is an essential process in order to collect data for analysis in the most efficient and suitable way. To begin with, two are the main philosophies that define any research attempt: positivism andinterpretivist. Methods of research, researcher's position, sampling and data collection processes are some of the points that differentiate those philosophies. The basic difference lays on the beliefs of each one of them(Altinay and Paraskevas, 2008).

The aim is to provide insights regarding the perceptions of service quality among Greek and European guests, as well as to clarify if there are any differences in the way their perceptions are formed in order to contribute to the literature with regard to the Greek hospitality sector. 


\subsection{Research Instrument}

Recent research has shown that questionnaires are widely used when measuring guests' perceptions of service quality as they proved to be an appropriate tool for measuring guest satisfaction (Dedeoglou, et al. 2018). In the current study,data collection will be done via questionnaires which were distributed at the front desk of hotels in Athens, after gaining consent from the hotel's management. The procedure started on June2019 and was completed by July2019, during the dissertation process. This period was suitable due to the fact that the survey was conducted in the middle of seasonality in Athens, offering space for more adequate sample. The questionnaires were distributed to current hotel guests and people who have previous 4 or 5 star experience, as to enhance the validity of the survey, as by selecting based on probability sampling, it is more likely to be able to come to a conclusion for the population during the data analysis process (Groves, 2013).Part of this procedure will take in the hotel's premises as the study's respondents' environment is a variable that could provide further insights in terms of reminiscence (Greasley et al., 2013).

The survey questionnaire was adapted from Akbaba, (2006), in a study measuring guest satisfaction in a business hotel in Turkey. It consist of three parts; the first part encloses statements related to service quality dimensions seeking to identify guests' perceptions, applying a modified SERVQUAL scale introduced by Parasuraman et al. The aim is to measure both the expected and the experienced loyalty from the customer's point of view (Janinskas, et al. 2016). Measurement will be done by using a 5-point Likert type scale, where 1=Very Low and 5=Very High. Quality dimensions will be measured based on the Likert scale measurement.

The second part will be constructed in a way that reveals guests' assessments on the overall service qualityof the hotel in question.The third part entails information regarding the guest's gender, age, educational background, visiting frequency and nationality.

Norris, (1997), researched validity, as a concept in which people understand whether what they read are trustworthy and accurate. In both qualitative andquantitative research, validity can be spotted by errors and prejudices, concepts that are subject to human nature, thus it is difficult to be predicted. Lu, et al. (2003), in order to test the parameter of validity, handed the paper to be examined by experts related to the hospitality field before starting the distribution.

\subsection{Sampling}

The target population are guests who have visited a 4 or 5 star hotel in Greece. Due to the fact that it is rather impossible to study the whole population and in order to define the boundaries of this research, as it is mentioned in the second objective of the study, the sample will be native Greek guests and European ones, including British (Bak, 2011). In order to achieve that, the questionnaires were distributed to current and previous hotel guests as to enhance the validity of the survey, as by selecting 
based on random spreading sampling, the researcher can obtain adequate sample without required clustering factors (Kondo et al., 2014). Simple random sampling means that every unit of the population has the same possibilities to be selected and included in the overall sample (Bell, Bryman and Harley, 2019). One advantage of the method is that it is a more representative way to come to generalised conclusions for a population (Alvi, 2016). Lack of bias and simplicity are also considered as major advantages of the method (Investopedia, 2019), whereas time and cost are among its disadvantages. In the current study, 100 paper written questionnaires will be distributed.

In order to collect data from both native and foreigner population, a transcript both in Greek and English was designed. As it is imperative the message to be appropriately transferred in both languages, the questionnaires were tested and translated by a Certified translator, so as to be as thorough as possible while avoiding misinterpretations due to grammatical and syntax errors (Ekinci, Prokopaki and Cobanoglu, 2003).

\subsection{Measurements}

\section{Empathy}

V5. Employees of the hotel appear neat and tidy (as uniforms and personal grooming)

V6. The hotel provides the services as they were promised

V13. Employees give guests individualized attention that makes them feel special

\section{Assurance}

V11. Employees have knowledge to provide information and assistance to guests in areas they would require (shopping, museums, places of interest, etc.)

V16. Employees have in-depth occupational knowledge (professional skills, foreign language, communication skills, etc.)

V15. Employees instill confidence in guests

V12. The hotel is also convenient for disabled guests (necessary arrangements made for the disabled)

\section{Responsiveness}

V7. Employees are always willing to serve customers

V14. The hotel provides its guests a safe and secure place

V10. The hotel provides flexibility in services according to guest demands

\section{Reliability}

V9. The hotel resolves guest complaints and compensate for the inconveniences guests go through 
V8. The hotel keeps accurate records (reservations, guest records, bills, orders, etc.)

V17. It is easy to access to the hotel (transportation, loading and unloading area, car parking area, etc.)

\section{Tangibles}

V1. The service unit of the hotel have adequate capacity (dining rooms, meeting rooms, swimming pools, business center facilities, etc.)

V2. The atmosphere and equipment are comfortable and appropriate for purpose of stay (beds, chairs, rooms, etc. comfortable, clean, and tranquil)

V3. The equipment of the hotel works properly without causing breakdowns

V4. Food and beverages served are hygienic, adequate, and sufficient

V5. Employees of the hotel appear neat and tidy (as uniforms and personal grooming) Upon collection, the data will be analyzed with the use of SPSS using multivariable analysis, PCA and Factor Analysis.

\section{Conclusions -Discussion}

This paper aims to explore the relationship between the perceived quality of services and the revisit intention in the 4 and 5 star hotels in Greece. Questionnaires, based on the SERVQUAL model will be used, in order to collect data from guests that have previously visited a 4 or 5 star hotel.

\subsection{Ethical considerations}

The ethical issues arising in quantitative research are also of importance as compared to the qualitative methods.An issue that social researchers come across when conducting research is the issue of confidentiality. Confidentiality declares the respect of the individual's autonomy and the importance of ensuring that disclosed information shall not be used purposely or accidentally in a way that the respondent becomes identifiable. Confidentiality is inextricably linked with anonymity. Even though, researchers often believe that they act on the best interest of the participants, it remains questioned whether by actively participate in a study they should allow the participants deliberately choose how their data will be used (Wiles et al. 2008). In the distribution of the self-completion questionnaires, a cover enclosing the details and the purpose of the study, the University's name as well as the researcher's information were in the front page. The issue of anonymity was highlighted and clarified in the cover page.

Following the above, according to the Social Sciences and Humanities Research Ethics Special Working Committee (SSHWC), several recommendations are illustrated respectfully, regarding privacy and confidentiality issues. The following:

1. "The right to confidentiality vs the right to recognition" 


\section{2. "Distinguishing "disclosure of" from "access to" information" \\ 3. "Ethics and Law" \\ 4. "Focus on Ethics" \\ 5. "Matters of Conscience and Responsibility" \\ 6. "Transparency, Openness and Accountability" (SSHWC, 2008)}

In order to achieve confidentiality and anonymity, a cover letter was handed to both the participants and the hotel management, asking their oral and written consent by signing the terms and conditions of the project. Their name is not revealed at any stage of the research. The only information that needed to be retrieved from the study is the participants'gender, age range, nationality and educational background. Plus, at any stage of the research, participants had the right to withdraw themselves from the process.

At this point, it is worth to mention that, whereas cultural diversity is measured it is crucial for the researcher to identify where he positions himself from the research subject and in what extend his knowledge may affect the measurement of the variables (Ying Yang and Le, 2008).

\subsection{Limitations}

In the design of this study, there are some limitations that should be taken into consideration. To begin with, the self-administered questionnaires will be filled by guests that were staying at a hotel at the time of the administration and by individuals that have previously used a hotel accommodation. This means that, there can be bias in terms in the timing of service use. Moreover, it would be adequate if there was also a qualitative research to support and implement the findings, so as to provide the reader with a more in-depth picture of the studied phenomenon. Another limitation can be found in the use of a modified SERVQUAL questionnaire, in terms of completeness of the data. Although SERVQUAL is widely used and accepted in the measurement of service quality, its modified version has received criticism in the literature and this is confirmed by Akbaba, (2006) whose words stated that " it needs to be adapted for the specific service environments and for the cultural context" (Akbaba, 2006 pp. 186).

\subsection{Results Prospects}

The findings can provoke useful tools for corporate processes planning and operations reengineering in the tourism industry.

\section{Acknowledgements}

This study is part of the ongoing Dissertation Submitted in fulfillment of the requirements of the Degree of Master in International Hospitality Management of Derby University (Mediterranean College Campus Greece) 


\section{References}

[1] Akbaba, A. (2006) 'Measuring service quality in the Hotel Industry: A study in a business hotel in Turkey', Hospitality Management, 25, pp. 170-192.

[2] Al-Ababneh, M. M. (2016) 'Employees' perspectives of service quality in hotels', Research in Hospitality Management, 6(2), pp. 189-193.

[3] Ali, F., Amin, M. and Cobanoglu, C. (2016) 'An Integrated Model of Service Experience, Emotions, Satisfaction, and Price Acceptance: An Empirical Analysis in the Chinese Hospitality Industry', Journal of Hospitality Marketing \& Management, 25(4), pp. 449-475.

[4] Altinay, L. and Paraskevas, A. (2008) Planning Research in Hospitality and Tourism, USA: Butterworth-Heinemann.

[5] Alvi M. (2016) 'A Manual for Selecting Sampling Techniques in Research', [Online]. Available at: https://mpra.ub.uni-muenchen.de/70218/ MPRA Paper No. 70218, (Accessed: 16 December 2018).

[6] American Marketing Association, (2008) 'The American Marketing Association Releases New Definition for Marketing' [online]. Available at: https://archive.ama.org/archive/AboutAMA/Documents/American\%20Mar keting\%20Association\%20Releases\%20New\%20Definition\%20for\%20Mar keting.pdf (Accessed: 11 March 2018).

[7] Bak, O. (2011) 'The Role of Qualitative Research in a Mixed Methods Study Assessing the e-Business Enabled Transformation in a Strategic Business Unit', Qualitative Research Journal, 11(2), pp.76-84.

[8] Baker, M.A. and Magnini, V.P. (2016) 'The evolution of services marketing, hospitality marketing and building the constituency model for hospitality marketing', International Journal of Contemporary Hospitality Management, 28(8), pp. 1510-1534.

[9] Barlas, A., Mantis, K. and Koustelios, A. (2010) 'Achieving positive word-ofmouth communication: The role of perceived service quality in the context of Greek ski centres', World Leisure Journal, 52(4), pp. 290-297.

[10] Benavides-Velasco, C. A., Quintana-García, C. and Marchante-Lara, M. (2014) 'Total quality management, corporate social responsibility and performance in the hotel industry.' International Journal of Hospitality Management, 41, pp. 77-87.

[11] Buhalis, D. (2001) 'Tourism in Greece: Strategic Analysis and Challenges', Current Issues in Tourism, 4(5), pp. 440-480.

[12] Chi, G. C. and Gursoy, D. (2009) 'Employee satisfaction, customer satisfaction, and financial performance: An empirical examination', International Journal of Hospitality Management, 28, pp. 245-253.

[13] Christou, E. (2015) Branding Social Media in the Travel Industry. ProcediaSocial and Behavioral Sciences, 175, pp. 607-614.

[14] Christou, P., Avloniti, A. and Farmakia, A. (2019) 'Guests' perceptions of emotionally expressive and non-expressive service providers within the 
hospitality context', Cyprus International Journal of Hospitality Management, 76, pp. 152-162.

[15] Costa, G. and Glinia, E. (2004) 'Sport tourism in Greece', Journal of Sport \& Tourism, 9 (3), pp. 283-286.

[16] Crick, A. P. and Spencer, A. (2011) 'Hospitality quality: new directions and new challenges' International Journal of Contemporary Hospitality Management, 23 (4), pp.463-478.

[17] Dedeoglou, B. B., Bilgihan, A., Ye, B. H., Buonincontri, P. and Okumuse, F. (2018) 'The impact of servicescape on hedonic value and behavioral intentions: The importance of previous experience', International Journal of Hospitality Management, 72, pp. 10-20.

[18] Ekinci, Y., Prokopaki, P. and Cobanoglu, C. (2003) 'Service quality in Cretan accommodations: marketing strategies for the UK holiday market.' Hospitality Management, 22, pp. 47-66.

[19] Eshetie, S. K., Seyoum, W., and Ali, S. H. (2016) 'Service Quality and Customer Satisfaction in Hospitality Industry: The Case of Selected Hotels in Jimma Town, Ethiopia.' Global Journal of Management and Business Research: E Marketing, 16(5), pp. 72-86.

[20] Garvin, D., A. (1988) 'Managing quality: the strategic and competitive edge', London: Collier Macmillan.

[21] Ghobadian, A., Speller, S. and Jones, M. (1994) 'Service Quality Concepts and Models.' International Journal of Quality \& Reliability Management, 11(9), pp. 43-66.

[22] Greasley, A., Lamont, A. and Sloboda, J. (2013) 'Exploring Musical Preferences: An In depth Qualitative Study of Adult's Liking for Music in Their Personal Collections', Qualitative Research in Psychology, 10(4), pp. 402-427.

[23] Grönroos, C. (1984) 'A Service Quality Model and its Marketing Implications', European Journal of Marketing, 18(4), pp. 36-44.

[24] Groves, M. R. (2013) Survey Methodology. Udo library [online]. Available at: https://www-dawsoneracom.ezproxy.derby.ac.uk/readonline/9781118627327(Accessed: 1 February 2018).

[25] Hosseini, R. S., Zainal, A. and Sumarjan, N. (2015) 'The Effects of Service Performance of Hotel Customers on Quality of Experience and Brand Loyalty in Iran', Procedia - Social and Behavioral Sciences, 201, pp.156 - 164.

[26] Hu, H., Kandampully, J. and Juwaheer, T. V. (2009) 'Relationships and impacts of service quality, perceived value, customer satisfaction, and image: an empirical study', The Service Industries Journal, 29(2), pp. 111-125.

[27] Ingram, H. and Daskalakis, G. (1999) 'Measuring quality gaps in hotels: the case of Crete', International Journal of Contemporary Hospitality Management, 11(1), pp.24-30. 
[28] Jasinskas, E., Streimikiene, D., Svagzdiene, B. and Simanavicius, A. (2016) 'Impact of hotel service quality on the loyalty of customers.' Economic Research-EkonomskaIstraživanja, 29(1), pp. 559-572.

[29] Jung, H., S. and Woon, H., H. (2016) 'What does work meaning to hospitality employees? The effects of meaningful work on employees' organizational commitment: The mediating role of job engagement.' International Journal of Hospitality Management, 53, pp. 59-68.

[30] Kandampully, J. (2006) 'The new customer-centered business model for the hospitality industry', International Journal of Contemporary Hospitality Management, 18 (3), pp.173-187.

[31] Kandampully, J. and Suhartanto, D. (2013) 'The Role of Customer Satisfaction and Image in Gaining Customer Loyalty in the Hotel Industry', Journal of Hospitality \& Leisure Marketing, 10(1-2), pp. 3-25.

[32] Karatepe, O. M. and Avci, T. (2002) Measuring Service Quality in the Hotel Industry: Evidences from Northern Cyprus, Anatolia, 13 (1), pp. 19-32.

[33] Kim, B. Y. and Oh, H. (2004) 'How do hotel firms obtain a competitive advantage?', International Journal of Contemporary Hospitality Management, 16 (1), pp.65-71.

[34] Kim, M., Knutson, J. B. and Han, J. (2015) 'Understanding Employee Delight and Voice From the Internal Marketing Perspective', Journal of Hospitality Marketing \& Management, 24(3), pp. 260-286.

[35] Lee, Y. L. and Hing, N. (1995) 'Measuring quality in restaurant operations: an application of the SERVQUAL instrument', International Journal of Hospitality Management, 14(3/4), pp. 293-310.

[36] Lewis, R. C., (1987) 'The measurement of gaps in the quality of hotel services.' International Journal of Hospitality Management, 6(2), pp. 83-88.

[37] Lo, A., Wu, C. and Tsai, H. (2015) 'The Impact of Service Quality on Positive Consumption Emotions in Resort and Hotel Spa Experiences', Journal of Hospitality Marketing \& Management, 24(2), pp. 155-179.

[38] Lu, C., Berchoux, C., Marek, M. W. and Chen, B. (2015) 'Service quality and customer satisfaction: qualitative research implications for luxury hotels', International Journal of Culture, Tourism and Hospitality Research, 9(2), pp.168-182.

[39] Luo, Z. and Qu, H. (2016) 'Guest-Defined Hotel Service Quality and Its Impacts on Guest Loyalty', Journal of Quality Assurance in Hospitality \& Tourism, 17(3), pp. 311-332.

[40] Martin, D. W. (1995) 'An Importance/Performance Analysis of Service Providers' Perception of Quality Service in the Hotel Industry,' Journal of Hospitality \& Leisure Marketing, 3(1), pp. 5-17.

[41] Mei, A. W. O., Dean, A. M. and White, C. J. (1999) 'Analyzing service quality in the hospitality industry', Managing Service Quality: An International Journal, 9 (2) , pp.136-143. 
[42] Minh, N. H., Ha, N. T., Anh, P. C. and Matsui, Y. (2015) 'Service Quality and Customer Satisfaction: A Case Study of Hotel Industry in Vietnam.' Asian Social Science, 11(10), pp. 73-85.

[43] Murphy, J., Schegg, R., and Olaru, D. (2007) 'Quality Clusters: Dimensions of hotel responses by luxury hotels.' Hospitality Management, 26, pp. 743-747.

[44] Norris, N. (1997) 'Error, Bias and Validity in Qualitative Research', Educational Action Research, 5(1), pp. 172-176.

[45] Papadimitriou, D. (2013) 'Service Quality Components as Antecedents of Satisfaction and Behavioral Intentions: The Case of a Greek Carnival Festival', Journal of Convention \& Event Tourism, 14(1), pp. 42-64.

[46] Papadimitriou, P, Boussia, N. and Trakas, T. (2016) 'In Focus: Greece', Hospitality net [online]. Available at: https://www.hospitalitynet.org/opinion/4078823.html (Accessed: 26 March 2018).

[47] Parasuraman, A., Berry, L. L. and Zeithaml, A. V. (1988) 'SERVQUAL: A Multiple-Item Scale for Measuring Consumer Perception of Service Quality.' Journal of Retailing Greewich, 64(1), p. 12.

[48] Pizam, A. (2015) 'Is empathy essential for high-quality customer service?' International Journal of Hospitality Management, 49, pp. 149-150.

[49] Pizam, A. and Holcomb, J. (2008) International Dictionary of Hospitality Management. Udo Library [online]. Available at: https://www-dawsoneracom.ezproxy.derby.ac.uk/readonline/9780080561271 (Accessed: 3 January 2018)

[50] Ramanathan, U. and Ramanathan, R. (2011) 'Guests' perceptions on factors influencingcustomer loyalty: An analysis for UK hotels', International Journal of Contemporary Hospitality Management, 23 (1), pp.7-25.

[51] Social Sciences and Humanities Research Ethics Special Working Committee (SSHWC) (2008) 'Privacy and Confidentiality' [online]. Available at: https://www.sfu.ca/ palys/SSHWC-

RecommendationsRePrivacyAndConfidentiality2008.pdf (Accessed: 25 January 2018).

[52] Strombeck, S. and Shu, S. (2014) "Modeling contextually elicited service quality expectations", Managing Service Quality, 24(2), pp.160-183.

[53] Theodorakis, N., Goulimaris, D. and Gargalianos, D. (2003) 'The relationship between service quality and behavioral intentions for spectators at traditional dance performances in Greece', World Leisure Journal, 45(1), pp. 53-61.

[54] Torres, E. N. (2014) ‘Deconstructing Service Quality and Customer Satisfaction: Challenges and Directions for Future Research', Journal of Hospitality Marketing \& Management, 23(6), pp. 652-677.

[55] Weane, N. and Morrison, J. A. (2013) Hospitality Marketing.Udo library [online]. Available at: www.dawsonera.com.ezproxy.derby.ac.uk (Accessed: 24 November 2017). 
[56] Weiermair, K. (2000) 'Tourists' perceptions towards and satisfaction with service quality in the cross-cultural service encounter: implications for hospitality and tourism management', Managing Service Quality: An International Journal, 10 (6), pp. 397-409.

[57] Wiles, R., Crow, G., Heath, S. and Charles, V. (2008) 'The Management of Confidentiality and Anonymity in Social Research',International Journal of Social Research Methodology,

[58] Williams, C. (1998) 'Is the SERVQUAL model an appropriate management tool for measuring service delivery quality in the UK leisure industry?', Managing leisure, 3(2), pp. 98-110.

[59] Witt, S. F and Moutinho, L (1995) Tourism Marketing and Management Handbook, Student edn. Europe: Prentice Hall.

[60] Worsfold, K., Fisher, R., McPhail, R., Francis, M. and Thomas, A. (2016) 'Satisfaction, value and intention to return in hotels', International Journal of Contemporary Hospitality Management, 28 (11), pp.2570-2588.

[61] Wu, H. and Ko, Y. J. (2013) 'Assessment of Service Quality in the Hotel Industry', Journal of Quality Assurance in Hospitality \& Tourism, 14(3), pp. 218-244.

[62] Yilmaz, I. (2009) 'Measurement of Service Quality in the Hotel Industry,' Anatolia, 20(2), pp. 375-386.

[63] Ying Yang, G. and Lê, T. (2008) 'Cultural and Political Factors in Conducting Qualitative Research in China', Qualitative Research Journal, 8(2), pp.113123. 